\title{
Chapter 28 \\ Older-Age Exclusion and the 2030 Agenda for Sustainable Development
}

\author{
Patricia Conboy
}

\subsection{Introduction}

The 2030 Agenda for Sustainable Development incorporating 17 Sustainable Development Goals (SDGs) was adopted by United Nations Member States in 2015 as a transformative agenda for economic, social and environmental development. Critically, from the perspective of older-age exclusion, the commitments of the 2030 Agenda are global, applicable in all countries; explicitly inclusive of people of all ages, therefore incorporating older people; and are founded on a central pledge to "Leave no one behind", aiming to reach the furthest behind first (United Nations 2015). Given these parameters, the 2030 Agenda has the potential to advance the recognition and rights of older people through bringing them into the mainstream of development policy and practice at global and national levels. The purpose of this chapter is to explore how far the potential of the 2030 Agenda has been realised as a global framework to address multidimensional older-age exclusion.

\subsection{Exploring Older-Age Exclusion}

In this chapter, older-age is understood as the latter stages of the life course (HelpAge International 2016), with older-age exclusion defined as a multidimensional process leading to inequities for older people in access to resources, power and rights in six domains conceptualised by Walsh et al. (2017). The domains cover material resources; social relations; civic and political participation; services; neighbourhood and community; and, of central importance in this chapter, socio-cultural aspects of society [see Torres et al. this volume for a discussion]. The socio-cultural

P. Conboy $(\bowtie)$

HelpAge International, London, UK

e-mail: Patricia.Conboy@ helpage.org 
domain [referred to in the wider book under the term civic exclusion - see Walsh et al. this volume] embraces ageism, symbolic exclusion and identity exclusion. Ageism is identified as treating people unfairly because of their age (HelpAge International 2019b). Symbolic exclusion is defined as "negative representations such as when older people are portrayed as marginal or valueless" and identity exclusion as the transfer of a partial identity to an individual or a group as their sole identity, dismissing or ignoring their multiple and distinctive identities (Grenier and Guberman 2009).

In focusing on the socio-cultural aspects of exclusion, this chapter considers whether and how ageing and older people are recognised in the framing, implementation, monitoring and reporting of the 2030 Agenda. It does so through a selective review of the grey literature published between 2015 and 2019, including UN reports, selected national government and civil society reports, related websites and conference reports. The emphasis is on experience in low- and middle-income countries and Sub-Saharan Africa in particular where countries face extreme challenges in implementing the SDGs. Two thirds of African countries are in the "low human development" category and continue to struggle with healthcare and education and the SDG funding gap is estimated at between \$5 billion and \$1.2 trillion annually (SDG Center for Africa 2019).

\subsection{The Sustainable Development Goals}

The Sustainable Development Goals (SDGs) aim to eradicate extreme poverty by 2030, to realise the human rights of all and to ensure that all human beings can fulfil their potential in dignity and equality and in a healthy environment (see Fig. 28.1). They are broader in scope and ambition than the UN Millennium Development Goals (MDGs) which preceded the 2030 Agenda and expired in 2015. With their breadth and focus on an integrated approach, the SDGs do offer opportunities to address both specific dimensions of exclusion and the interaction between multiple domains of exclusion for people of all ages. The detail of the SDGs is articulated in 169 specific targets and 230 indicators intended to track progress on their implementation (Inter-Agency and Expert Group on Sustainable Development Indicators 2016).
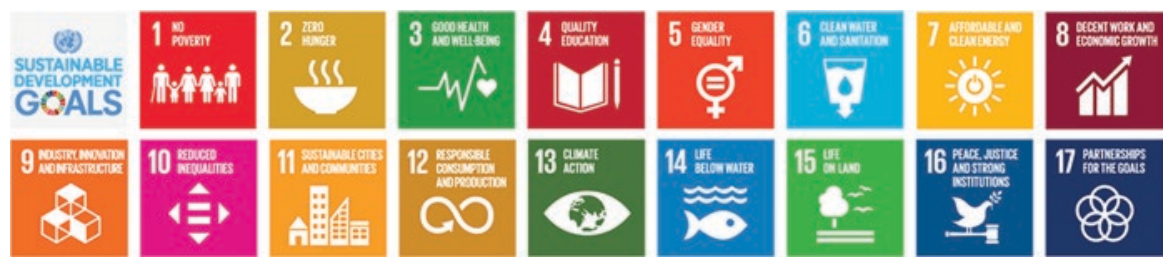

Fig. 28.1 The sustainable development goals 
The 2030 Agenda provides a global framework for action which UN Member States then implement at a national level. Member States participate in the SDG process on a voluntary basis, each determining the scope and nature of their involvement and national approaches to implementation, monitoring and reporting on progress. Governments are invited to submit Voluntary National Reviews (VNRs) to the High-Level Political Forum (HLPF), the central platform for annual review and follow-up of the 2030 Agenda and the SDGs. While UN guidance is provided, national governments choose what they include in the VNRs.

\subsection{Significance of the 2030 Agenda for Sustainable Development}

The 2030 Agenda shapes the global conversation on development. If older people and ageing are recognised in the 2030 Agenda, they form part of a global conversation between key policymakers and influencers. If not, older people are in effect "left behind". This is of particular relevance to policy agendas in low- and middleincome countries where, in contrast with high-income countries, the issue of demographic ageing has received less political attention. All of the UN entities have aimed to align their strategic programmes of work with the Agenda and the SDGs (United Nations, Economic and Social Council 2018). These include bodies such as the regional economic commissions and multilateral agencies such as the United Nations Development Programme (UNDP), the World Health Organization (WHO) and the World Bank. National and institutional donor agencies and aid programmes also align their strategies and their funding priorities with selected elements of the 2030 Agenda.

The overall effects apply to the period to 2030 and beyond in that the SDGs are likely to be succeeded by a new UN development agenda. While the MDGs did not recognise older people and ageing, the SDGs do offer space for recognition. Whether or not this space is extended and mainstreamed in a post-2030 UN agenda will be influenced by the degree to which older-age exclusion becomes part of global and national policy agendas up to 2030 .

There are other pressing reasons why the 2030 Agenda is significant. It is an immediate driver of global action on policies relevant to older people. Health is an example, with SDG3 promoting access to affordable and quality health services for all under the banner of universal health coverage (UHC). While there are stated commitments across the UN, national governments and civil society to UHC, policies and programmes, the risk of omission of older people from UHC implementation remains high. There are similar patterns across other policy areas of significance such as gender equality, access to income and employment, and disability inclusion.

As with any other global framework, the 2030 Agenda absorbs energy and attention within the matrix of processes involving governments, multilateral entities, civil society organisations and other stakeholders who constitute "the development 
system". As well as VNRs (47 in 2019), there are policy audits, budgetary analyses, new committees and consultations with stakeholders. When there are failures to address the issues of key population groups, there is an opportunity cost in terms of misplaced energy. From the perspective of older people, this channelling of energy represents paradoxically both an opportunity for age mainstreaming and a risk of deepening multidimensional exclusion. It can be said with reasonable confidence that most older people are unaware of commitments by their governments to the delivery of the 2030 Agenda and the SDGs. The corollary is that they are missing out on chances to hold governments to account for delivery on commitments that would make a material difference to enjoyment of their rights and quality of life in older-age.

\subsection{Older-Age Exclusion in Low- and Middle-Income Countries}

While growing old is not a new human experience, the way people are ageing is new. People are living longer and in larger numbers and, globally, later life has become a less predictable and more fluid part of the life course. The scale of the challenge countries face in adapting to the demographic transitions they are now experiencing is immense. The largest share of the world's older people (37\%) live in Eastern and South Eastern Asia and this is the region where the speed of population ageing is fastest (UNDESA 2019). Though the share of older people in SubSaharan Africa looks small by comparison (5\%), the numbers involved are large. There are 31.9 million people aged 65 and over living in Sub-Saharan Africa. Notably, while the 2030 Agenda presents a call to transform our world, it does not incorporate consideration of demographic ageing in its founding documents (United Nations 2015).

In terms of older-age exclusion, there are difficulties in characterising the experience of older people across regional and national settings where political, cultural, socio-economic and demographic landscapes are extraordinarily diverse and varied. However, there are sufficient data to establish that older persons do experience systematic, multidimensional exclusion as conceptualised by Walsh et al. (2017) in the form of lack or denial of rights, resources, goods and services as they age. Worldwide, $68 \%$ of people above retirement age receive an old-age pension. In Sub-Saharan Africa, $22.7 \%$ do so and in Southern Asia the figure is $23.6 \%$ (ILO 2017). In terms of access to health and care services and supports, older people are under-served. As an illustration, in most high-income countries, under half of people living with dementia have received a diagnosis. From the limited data available in LMIC settings, it is estimated that no more than $5-10 \%$ of people living with dementia have received a diagnosis, and specialist continuing care is extremely limited (HelpAge and AARP 2018). There is also sufficient evidence available from consultations 
with older people to establish that they do experience ageism in countries of all levels of development (Ayalon and Tesch-Römer 2018; Phoenix and Parravani 2019).

In terms of trajectories of older-age exclusion, the interaction between demographic ageing and other mega trends such as the growth of artificial intelligence and digital technologies, migration trends, rising inequalities and climate change will have a bearing on how people age in future decades. For example, a person in the Asia Pacific region is five times more likely to be affected by disasters than anywhere else in the world and those disasters have a disproportionate impact on older people (HelpAge International 2019c).

\subsection{Framing a Whole Population Group as Vulnerable}

Where older people are identified in Agenda 2030, they are primarily included with other groups characterised as "vulnerable", including children, persons with disabilities and refugees (United Nations 2015; Republic of Rwanda 2019; SDGs Kenya Forum 2019; United Republic of Tanzania 2019). How a group or issue is presented or framed affects the ways in which people react and respond to that group or issue. Frames are ways of thinking that shape the way people see the world. A frame effect is said to occur when people react differently to a social or scientific issue as a result of the way it is framed, for example whether it is presented as a loss or a gain, or a problem that affects individuals or society (Frameworks Institute 2019).

The framing of a whole population group, in this case older people, as vulnerable solely on the basis of their chronological age raises serious questions. It is factually inaccurate. Older populations are characterised by both diversity and inequality. It is unscientific in that, as research evidence has demonstrated, the relationship between chronological age and human functioning and capacity is far from straightforward (Beard and Bloom 2015). It is at odds with the evidence available to us of older people's own views and preferences. In consultations across a range of lowand middle-income settings, older people have consistently identified their preferences and priorities. These include voice, visibility, respect, participation, an emphasis on autonomy, independence and choice in living their lives, and on recognition of their rights (Sleap 2019a, b). Older people seek equality and parity of esteem with others and inclusion in the mainstream, not special treatment as a distinct group outside the mainstream of society. This "vulnerability" framing also contradicts the framing of the 2030 Agenda as a transformative vision for society rooted in human rights principles.

While the concept of "vulnerable groups" has been used to argue for the protection of human rights of groups, such as members of the Roma community, asylum seekers and people with impaired health or abilities in European courts of law, risks associated with use of the concept have been identified in a critical assessment (Peroni and Timmer 2013). Concerns relate to the potential danger of reinforcing vulnerability "by essentialising, stigmatising, victimising and paternalising" a 
group. Essentialising occurs when significant differences within the group are obscured and they are homogenised regardless of, for example, health or cognitive status, individual preferences and aspirations. Stigmatising occurs when the term "vulnerable" carries connotations of harm or injury for the members of the group themselves. Paternalising occurs when the agency and autonomy of members of the group is denied and protection is imposed on them (Peroni and Timmer 2013, pp. 1070-73). A further nuance relates to the perspective from which protection is provided. From a charity perspective, support is available to the "deserving" poor and groups seek to establish that they deserve support. In the case of older people, this sometimes takes the form of the contribution argument which focuses on quantifying their economic contributions as carers, grandparents, volunteers, community development activists and such. In these attempts to counter the "burden" narrative that dominates discourse on population ageing, proponents of the contribution argument may, in the view of the author, unwittingly deepen the socio-cultural exclusion of older people (European Commission 2015).

The categorisation of older people as a vulnerable group in the 2030 Agenda, while reflective of mainstream approaches in the development sector, is misguided. It undermines the rights of older people. It also reinforces the failure to identify ageism as a key driver of the discrimination and exclusion evident in the design and implementation of laws, policies, and programmes that should serve people equally across the life course. A further irony is that, while the pledge to "Leave no one behind" has opened the space for identification and inclusion of groups typically at high risk of exclusion, the way in which this space has been used to reinforce the categorisation of older people as a vulnerable group is proving counterproductive. It fails to identify older people as rights holders and governments as duty bearers in their regard. Yet this is precisely the breakthrough that is required if older-age exclusion is to be addressed effectively globally and nationally.

\subsection{Implementation of the 2030 Agenda and the Sustainable Development Goals}

The explicit recognition of older people and ageing in the SDGs is limited. With SDG1, promoting the eradication of poverty and SDG3, promoting health and wellbeing, the goals clearly refer to people of all ages. Otherwise, the only explicit references to older people are in SDG2.2 which focuses on malnutrition among older people and SDG11 on sustainable cities and communities which identifies the need to consider older people in widening access to public transport and access to green spaces. Generalised statements about people "of all ages" are meaningless when older people are effectively eliminated from delivery of the SDGs, as happens when benchmarks are age-capped. For example, while SDG 5.6 advocates universal access to sexual and reproductive health and rights, the indicators measuring the goal are capped at 49 years. Evidence about the implementation of the SDGs is 
largely derived from the reports of the UN Secretary General to the HLPF and the VNRs submitted by individual Member States. With the exception of a single ageing-specific report to the General Assembly, based on research commissioned by the UN Focal Point on Ageing, the coverage of older people in these documents is patchy and superficial. In general, the evidence that is available is descriptive rather than analytical with little detail on the implementation of policies or the outcomes for older people (UN 2019).

Findings from a recent Tanzanian study illustrate the importance of more granular analysis of policy implementation at national levels (HelpAge International and AARP 2019). While national policy in Tanzania provides for free access to public health services for people aged 60 and over by means of a waiver scheme, there are significant gaps in implementation. These include reluctance on the part of some health service providers at local levels to extend free services. This is due to a conflicting policy demand to recover local costs from service users. The result is an incentive to prioritise patients who can pay for services. In addition, older people themselves are not always sure about their right to the services or how to exercise this right. Issues on which they need support include accessing the waiver cards that would establish their age and entitlement to a health service, and a process for making complaints or seeking redress when they were denied access to services or receive a poor service, for example partial filling of prescriptions for medicines. These findings also point to the value of a multidimensional analysis of older-age exclusion in illustrating how forms of discrimination reinforce each other in different domains; in this example, material, political, services and socio-cultural domains.

\subsection{Evidence from the National Level in Low- and Middle-Income Settings}

The evidence base on the implementation of policy on ageing and older people in low- and middle-income countries is thin, and even more sparse in terms of tracking policy implementation associated with the influence of the SDGs. In a review of experience from small-scale SDG pilot programme interventions in eight countries, it was found that national partners faced a number of common challenges when advocating for the recognition of older people in the SDGs. Critically, these included a broad lack of awareness among policymakers, civil society groups and older people about the links between ageing and sustainable development issues (HelpAge International 2019a). What this meant in practice was that, for some countries preparing their VNRs, ageing was not considered or that government focal points on ageing were not consulted. Even when awareness was raised and stakeholders appeared sympathetic, this did not necessarily trigger action due to competing priorities or staff being moved to other departments. Partners reported that, when trying to establish themselves in key policy spaces, they found that the person in 
government working on ageing was not always involved in the SDG process and those working on the SDGs were not aware of the links with ageing. There were additional challenges in some governments where the ownership of SDGs rested with multiple departments without a central coordination structure. This made it difficult for civil society partners with limited resources to engage with all the key players. The complexity of these implementation processes is another barrier to older people's participation in the 2030 Agenda.

\subsection{Visibility of Older People and Ageing in Monitoring and Reporting of the SDGs}

An analysis of statistical reporting on progress of the SDGs at global level illustrates the near invisibility of older people and ageing in the process (United Nations 2019). The indicators presented are those for which data are available. In the case of older people, reporting is confined to social protection floors under SDG1. The targets and indicators for which data on older people are not reported due to underlying deficiencies in the data include malnutrition, HIV infection, mortality attributed to non-communicable diseases (NCDs), access to universal health coverage, to education and lifelong learning, gender equality, employment and unemployment, coverage by mobile phone network, deaths due to disasters, experience of sexual violence and access to legal identity. This goes against the commitment of SDG17 to increase the availability of reliable data disaggregated by income, gender, age, disability, ethnicity, migratory status and other characteristics. While the 2030 Agenda has led to a proactive focus on data development and disaggregation and there are positive initiatives on ageing-related statistics, such as the establishment of the Titchfield City Group (Pullinger 2018), there is a systemic bias towards addressing data gaps for younger age groups. Age data gaps and discriminatory age caps will continue to hinder the monitoring of older-age exclusion in the 2030 Agenda.

\subsection{Mainstreaming of Ageing and of Older People}

It is evident from this review that the potential of the 2030 Agenda as a framework to address multidimensional older-age exclusion is not being maximised. If anything, the findings about framing and visibility of older people suggest the risk of deepening socio-cultural exclusion over the lifetime of the 2030 Agenda. How then to address these concerns in practice?

The development of coherent policy on ageing is not straightforward. Beard and Bloom (2015) have highlighted several of the challenges, including the complexity of the changes that constitute and affect ageing; the loose correspondence between chronological ageing and functional ability and capacity; and the inter-individual 
variability and diversity of older populations. They point out that the variability is not random and that, while some heterogeneity in health and function is genetically determined, the major proportion is strongly affected by the cumulative effect of health behaviours and inequities across the life course. Other issues identified include the rigid use of a policy framework typically based on a three-stage life cycle of student, working life and retirement which "reinforces ageist stereotypes and prevents the flexible forms of participation older people are increasingly seeking" (Beard and Bloom 2015). In their conceptualisation of old-age exclusion, Walsh et al. (2017) have identified key domains and also pointed to unique features of older-age exclusion including the accumulation of disadvantage over the life course and the greater susceptibility of some older people to marginalisation. While these dimensions are typically well understood by academics, professionals and practitioners in the fields of gerontology, geriatrics and ageing, they are not well embedded in many arenas of the policy world.

\subsection{The Gap Between Knowledge on Ageing and Policy Action on Ageing}

The reality is that there are knowledge translation gaps between the professional "ageing" world and significant policy arenas including that of the 2030 Agenda. While there is concerted action to influence policy on ageing, the responses of political leaders fall short (Stakeholder Group on Ageing 2019). There are bodies of research knowledge and empirical experience that stakeholders could use better to influence policy design on older-age exclusion. These include an extensive literature on the process of knowledge translation incorporating the steps between the creation of new scientific knowledge, its synthesis, dissemination, exchange and application to yield useful outcomes for society (Straus et al. 2009). Dissemination and exchange, stemming as they do from research evidence, include but go beyond communications strategies (Barwick et al. 2014). Traditional approaches to communications strategies based on publication of a research report, launch and press release will have no impact on policy implementation, but the communications world is vibrant with new strategies, platforms and approaches that can boost the effectiveness of knowledge translation processes (Cast from clay 2018).

\subsection{Policymaking is a Political Process}

There is also an extensive literature on policy implementation, identifying the political nature of the policymaking process (Tilley et al. 2017; Viennet and Pont 2017). Barr and Crawford (2005) describe the three legs of the policy reform tripod as policy design, political implementation and administrative/technical implementation. A 
case study based on empirical experience of advocacy for a universal social pension in Malawi illustrates the political dimensions of policy influencing (Juergens 2019). This advocacy has been led by a Malawi network of older persons' organisations, MANEPO, and directed towards Ministries, parliament and the media. A feasibility study, developed jointly by the Malawi Ministry for Social Welfare and a civil society partner, provided evidence and direction for their advocacy, enabling a shared understanding and consensus among the key stakeholders. As an effective national champion, MANEPO's leader played a critical role in terms of his understanding of national political dynamics, his connections to politicians, media, editors and parliamentarians, and his nuanced understanding of the legislative process. Another key factor was the development of effective partnerships between the national network, civil society and multilateral partners to augment technical capacity and share strategic intelligence. They were successful in achieving the drafting of a draft Social Pension Bill immediately before the 2019 General Election. Advocacy activities require financial support and the fourth enabling factor was sustained and flexible funding from Irish aid.

\subsection{Technical/Administrative Implementation}

While the 2030 Agenda advocates an integrated approach to economic, social and environmental policy, little guidance is given on the technical and administrative challenges of cross-sectoral policymaking. Traditionally, government departments work within silos and dedicated budget lines. Policymakers must break new ground to implement cross-cutting approaches. In terms of multidimensional older-age exclusion, it is precisely these kinds of cross-cutting approaches that are required but hard to achieve. Typical issues include political failure to build support for national policy commitments among frontline and regional staff; to establish effective processes for multisectoral coordination; and to support implementation with action plans and budgets. One place where there is practical knowledge emerging is New Zealand, which has implemented a well-being budget breaking down traditional silos of government to agree a limited number of well-being priorities backed up by evidence on policy impacts (Government of New Zealand 2019).

\subsection{Conclusion}

This chapter has explored how far the potential of the 2030 Agenda is being realised to address multidimensional older-age exclusion. A broad review has been conducted across the breadth of a global framework. The strength of this approach has been that it provides an overview for diverse interest groups at a crucial time for the 2030 Agenda. There have been 5 years to bed down the SDGs, but there is still a decade in which to make improvements. The limitation has been that broad 
brushstrokes have been applied to issues and contexts that are inherently complex and diverse with inevitable losses of nuance and subtlety and limits to explanatory power.

In terms of socio-cultural older-age exclusion, the key question was whether older people and ageing were recognised in the framing, implementation, monitoring and reporting of the 2030 Agenda. The finding is that recognition of ageing and older people is limited across each of these dimensions. Where there is explicit recognition, it takes place primarily within the framing of older people as a vulnerable group rather than as rights holders on an equal footing with people of other ages. The major shift required in this context is the recognition of older people as rights holders, of States as duty bearers and the extension of a rights-based approach to policy design and implementation to counteract multidimensional social exclusion. Unless there is a major shift in the coming decade, the pledge that the 2030 Agenda and the SDGs should be met for "all nations, peoples ... and segments of society" will not be achieved in the case of older people, and the risks of failure are highest for older people in low- and middle-income countries.

Failure is not inevitable. With the political commitment of key stakeholders, it is possible to make more effective use of the 2030 Agenda to address older-age exclusion at all levels. Partnership working with older people is essential. Other tools are available, as discussed in this chapter. These include a conceptual framework of older-age exclusion to support more effective policy influencing, design and implementation within the system; the more systematic use of relevant bodies of research knowledge and empirical experience, including those related to knowledge translation and policy implementation; and the use of more innovative communication strategies. In terms of research/policy networks aiming to advance knowledge sharing and policymaking regarding multidimensional older-exclusion, a Eurocentric perspective is insufficient. The participation of researchers, policymakers and older people from low- and middle-income countries would greatly strengthen impact in relation to the 2030 Agenda. Finally, recognition by multilateral and bilateral aid agencies of multidimensional older-age exclusion in the context of the 2030 Agenda would increase strategic impact and enable financial support for the policy influencing that needs to be done over the next decade.

\section{Author's Postscript}

The near invisibility of older people in statistical reporting on the SDGs at global level has already been identified as a concern in this chapter. During the pandemic, 80 per cent of surveyed national statistical offices (NSOs) in low- and middleincome countries (LMICs) reported that they were struggling to operate due to financial constraints and 90 per cent suggested that they were struggling to meet international reporting requirements (UNSD and World Bank 2020). Even before the pandemic, many NSOs struggled to produce good quality age-disaggregated data on older women and men in development and humanitarian contexts. The crisis 
has compounded those problems. In the main, the numbers of cases and fatalities from COVID-19 were being reported, but the production of data disaggregated by age and sex was much more limited (Mihnovits 2020). In addition, gaps in reliable data and evidence on underlying health conditions, access to essential health services and cause of death among older people will become even more pressing concerns for policymakers at both global and national levels as countries aim to recover and "to build back better" through the framework of the 2030 Agenda for Sustainable Development. Multilateral and donor agencies must ensure their pandemic response includes funding and technical support to NSOs in LMICs to sustain collection, analysis and reporting of timely data on ageing and older people during emergencies.

Acknowledgements This chapter benefitted from contributions by Alex Mihnovits, Flavia Galvani, Florian Juergens, Roseline Kihumba, Verity McGivern, Mark Gorman, Mariana Rudge and Camilla Williamson, HelpAge International, Professor Thomas Scharf, University of Newcastle, and Professor Kieran Walsh, NUI Galway.

\section{References}

Ayalon, L., \& Tesch-Römer, C. (2018). Contemporary perspectives on ageism. https://link. springer.com/content/pdf/10.1007\%2F978-3-319-73820-8.pdf. Accessed 8 Dec 2019.

Barr, N., \& Crawford, I. (2005). Financing higher education: Answers from the UK. London/New York: Routledge.

Barwick, M., Phipps, D., Myers, G., Johnny, M., \& Coriandoli, R. (2014). Knowledge translation and strategic communications: Unpacking differences and similarities for scholarly and research communications. Scholarly and Research Communications, 5, 1-14. https://doi. org/10.22230/src.2014v5n3a175.

Beard, J., \& Bloom, D. (2015). Towards a comprehensive public health response to population ageing. The Lancet, 385(99968), 658-661.

Cast from clay. (2018). A new model for think tank communications. Blog. https://castfromclay.co.uk/blog/2018/8/7/a-new-model-for-think-tank-communications-part-ii. Accessed 8 Dec 2019

European Commission. (2015). Growing the European silver economy. http://ec.europa.eu/ research/innovation-union/pdf/active-healthy-ageing/silvereco.pdf. Accessed 13 Dec 2019.

Frameworks Institute. (2020). How do we do it? https://www.frameworksinstitute.org/sfa-overview.html. Accessed 2 Nov 2019.

Government of New Zealand. (2019). The well-being budget 2019. https://treasury.govt.nz/sites/ default/files/2019-05/b19-well-being-budget.pdf. Accessed 8 Dec 2019.

Grenier, A., \& Guberman, N. (2009). Creating and sustaining disadvantage; the relevance of a social exclusion framework. Health \& Social Care in the Community, 17(2), 116-124.

HelpAge International. (2016, December). International glossary (Unpublished paper).

HelpAge International. (2019a, July). Ageing and the SDGs, ensuring visibility and inclusion of older people. London: HelpAge International.

HelpAge International. (2019b, August). Operational definitions (Unpublished paper).

HelpAge International. (2019c). An older world with increasing exposure to disasters. Infographic.

HelpAge International and AARP. (2018). Global AgeWatch insights, the right to health, the right to be counted. London: HelpAge International.

HelpAge International and AARP. (2019). Tanzania insights, the right to health and access to universal health coverage for older people. London: HelpAge International. 
Inter-Agency and Expert Group on Sustainable Development Goal Indicators. Final list of proposed Sustainable Development Indicators (E/CN.3/2016/2/Rev.1). https://sustainabledevelopment.un.org/content/documents/11803Official-List-of-Proposed-SDG-Indicators.pdf. Accessed 8 Dec 2019.

International Labour Organisation. (2017). World social protection report 2017-19. Geneva: ILO. Juergens, F. (2019). Supporting MANEPO's advocacy for the establishment of a universal social pension in Malawi (Unpublished paper).

Mihnovits, A. (2020, June). Official statistics and COVID-19, capturing evidence on older people for response and recovery. HelpAge International.

Peroni, L., \& Timmer, A. (2013). Vulnerable groups: The promise of an emerging concept in European human rights convention law. International Journal of Constitutional Law, 11(4), $1056-1085$.

Phoenix, C., \& Parravani, E. (2019). Older people's experiences of ageing and ageism in Serbia, Costa Rica, Pakistan and the Gambia. London: HelpAge International.

Pullinger, J. (2018). Why we need better data to improve the lives of ageing populations. https:// civilservice.blog.gov.uk/2018/12/13/why-we-need-better-data-to-improve-the-lives-of-ageing-populations/.Blog. Accessed 8 Dec 2019

Republic of Rwanda. (2019). 2019 Rwanda Voluntary National Review (VNR) report. https:// rwandaun.org/site/rwanda-voluntary-national-review-2019/.pdf. Accessed 3 Nov 2019.

Sleap, B. (2019a). Living, not just surviving. London: HelpAge International.

Sleap, B. (2019b). Keeping our dignity. London: HelpAge International.

Stakeholder Group on Ageing. (2019, September 24-25). Presentation by Roseline Kihumba on behalf of Stakeholder Group on Ageing to CSO Forum held during SDG Summit (Unpublished paper).

Straus, S. E., Tetroe, J., \& Graham, I. (2009). Defining knowledge translation. CMAJ, 181(3-4), 165-168. https://doi.org/10.1503/cmaj.081229.

The SDGs Kenya Forum. (2019). The second progress report on implementation of SDGs in Kenya, Civil Society Report 2019. http://planning.go.ke/wp-content/uploads/2019/07/ReformattedTemplate.pdf. Accessed 3 Nov 2019.

The Sustainable Development Goals Center for Africa, Sustainable Development Solutions Network. (2019). 2019 Africa SDG Index and Dashboards Report. https://sdgindex.org/ reports/2019-africa-sdg-index-and-dashboards-report/. Accessed 3 Nov 2019.

Tilley, H., Shaxson, L., Young, J., Rea, J., \& Ball, L. (2017). 10 things to know about how to influence policy with research. London: ODI.

United Nations. (2015). Transforming our world: The 2030 agenda for sustainable development, A/Res/70/1. https://sustainabledevelopment.un.org/post2015/transformingourworld/publication. Accessed 6 Dec 2019.

United Nations. (2019). Follow-up to the international year of older persons: Second world assembly on ageing (Report of the Secretary General to the General Assembly). https://undocs. org/A/74/170. Accessed 3 Nov 2019.

United Nations Department of Economic and Social Affairs (UNDESA). (2019). World population ageing 2019 highlights. New York: United Nations.

United Nations, Economic and Social Council. (2018). Report of the inter-agency and expert group on Sustainable Development Indicators. Note by the Secretary General to the Statistical Commission. https://unstats.un.org/unsd/statcom/50th-session/documents/2019-2-IAEGSDG-EE.pdf. Accessed 3 Nov 2019.

United Nations, Economic and Social Council. (2019). Special edition: progress towards the Sustainable Development Goals (Report of the Secretary General to the High Level Political forum on sustainable development. E/2019/68). https://unstats.un.org/sdgs/files/report/2019/ secretary-general-sdg-report-2019\%2D\%2DEN.pdf. Accessed 3 Nov 2019.

United Republic of Tanzania. (2019). Voluntary National Review (VNR) 2019, Empowering people and ensuring inclusiveness and equality. https://www.nbs.go.tz/index.php/en/sdg/428-volun- 
tary-national-review-vnr-2019-empowering-people-and-ensuring-inclusiveness-and-equality. pdf. Accessed 3 Nov 2019.

UNSD and World Bank. (2 June 2020). The global COVID-19 survey of National Statistical Offices, preview of main results presented at Open virtual meeting of the IAEG-SDG, Covid-19 impacts and resources on data collection, SDG monitoring and on vulnerable groups, 2 June 2020, https://unstats.un.org/sdgs/meetings/virtual-2jun2020/

Viennet, R., \& Pont, B. (2017). Education policy implementation: A literature review and proposed framework (OECD Education Working Paper No. 162). http://www.oecd.org/officialdocuments/publicdisplaydocumentpdf. Accessed 8 Dec 2019.

Walsh, K., Scharf, T., \& Keating, N. (2017). Social exclusion of older persons: A scoping review and conceptual framework. European Journal of Ageing, 14, 81-98. https://doi.org/10.1007/ s10433-016.

Open Access This chapter is licensed under the terms of the Creative Commons Attribution 4.0 International License (http://creativecommons.org/licenses/by/4.0/), which permits use, sharing, adaptation, distribution and reproduction in any medium or format, as long as you give appropriate credit to the original author(s) and the source, provide a link to the Creative Commons license and indicate if changes were made.

The images or other third party material in this chapter are included in the chapter's Creative Commons license, unless indicated otherwise in a credit line to the material. If material is not included in the chapter's Creative Commons license and your intended use is not permitted by statutory regulation or exceeds the permitted use, you will need to obtain permission directly from the copyright holder.

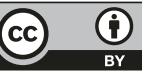

